\title{
EFEITO DE SISTEMAS DE FOTOATIVAÇÃO NA FORMAÇÃO DE MICROFENDAS MARGINAIS EM RESTAURAÇÕES CLASSE II
}

Giovana Mongruel GOMES, Gislaine Cristine MARTINS, João Carlos GOMES, Osnara Maria Mongruel GOMES, Abraham Lincoln CALIXTO

A contração de polimerização é o maior problema na adaptação marginal das restaurações em resina composta fotopolimerizável, causando a formação de fendas marginais. O objetivo foi avaliar a formação destas fendas em restaurações de resina composta classe II, utilizando um aparelho à base de lâmpada halógena (QTH), e dois à base de LEDs. Cavidades padronizadas foram executadas nas faces proximais de 18 terceiros molares humanos. Resina composta Filtek P60 (3MESPE) foi inserida por meio de uma ponta fotocondensadora e fotoativada usando três sistemas de fotoativação: GIOptilux401(QTH); GII-ColtoluxLED (LEDs) e GIII-UltraLumeLED5 (LEDs). Após o acabamento os dentes foram submetidos à ciclagem térmica à $5^{\circ} \mathrm{C} \pm 2^{\circ} \mathrm{C}$ e $55^{\circ} \mathrm{C} \pm 2^{\circ} \mathrm{C}$, realizando um total de 500 ciclos. Os dentes foram seccionados no sentido vestíbulolingual e depois no centro das restaurações. A extensão da fenda foi observada sob MEV com um aumento de 1000X. Os dados foram analisados através do teste não paramétrico de Kruskal-Wallis. Os valores médios da amplitude das microfendas foram: GI 3.28_3.34 $\mu \mathrm{m}$; GII 1.48 $\pm 1.89 \mu \mathrm{m}$ e GIII $3.11 \pm 3.45 \mu \mathrm{m}$. Concluiu-se que fendas marginais foram observadas em todos os grupos; e entre os aparelhos de fotoativação utilizados neste estudo não houve diferenças estatísticas significantes, apesar de uma tendência de melhor desempenho para o GII. 